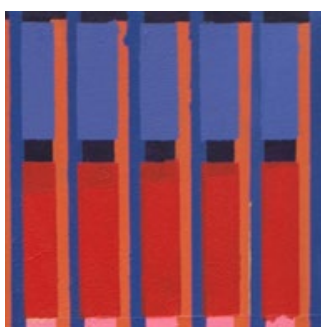

\title{
El espejo charrúa: la alteridad como reflejo
}

\author{
The Charrua Mirror: Otherness as a Reflection
}

\author{
Dario Arce Asenjo \\ Doctor en Etnología por la Universidad París III, \\ Francia. Investigador Asociado del CREDA, IHEAL, Paris. \\ arcedario@gmail.com
}

Recibido 28/06/2017 - Aceptado 30/08/2017

\section{RESUMEN}

Es conocida la historia de los denominados "últimos Charrúas" descrita por Paul Rivet, cuya trayectoria hemos podido describir aportando algún dato nuevo en un artículo precedente (Arce Asenjo, 2007). En el marco de este avance presentaré fragmentos traducidos de fuentes inéditas en Uruguay, artículos de la época, crónicas, que utilizaremos para enfocarnos en la manera en la que fue descripta su exhibición en París y como ésta serviría de pretexto (Bouysse-Cassagne, 1984) para emitir opiniones sobre la sociedad francesa de entonces. Este avance es parte de una investigación cuyo resultado debería ser la publicación de una versión reactualizada del trabajo de Paul Rivet, aún inédito en Francia, pero cuya "memoria" fue publicada por la Sociedad de Amigos de la Arqueología en Uruguay en 1930.

La presencia de los 4 Charrúas en París no pasó desapercibida. Es cierto que pocos años antes, en 1827, seis Osages habían llegado a la Ciudad-Luz para visitar a las autoridades y reclamar ante la corte francesa la situación de su pueblo en lo que no era todavía Canadá. Víctimas de la astucia de un tal Delaunay, que explotó su presencia, habían terminado transformándose en objeto de curiosidad para el público parisino y constituyeron de esa forma un precedente para la iniciativa de François de Curel de llevar a su vez a los charrúas hasta Paris.

Palabras clave: últimos charrúas; alteridad; Paul Rivet; Francois de Curel; Prosper Mérimée

\begin{abstract}
It's already well known Paul Rivet's "Last Charrúas" story and we have described its trajectory while adding some new facts in a previous article (Arce Asenjo, 2007). Now I will propose some fragments translated from unpublished in Uruguay sources, vintage articles, chronicles that we'll use to focus on how their Paris exhibition was shown and how it may by a pretext (Bouysse-Cassagne, 1984) to issue opinions on the French society at that time. This advance is
\end{abstract}


part of a research aimed to publish a revised edition on Paul Rivet's work, yet unpublished in France but its "memory" was published in 1930 by the Uruguayan Archaeology Friends Society.

The appearance of those four Charrúas didn't pass unnoticed at Paris. Of course, some time before, in 1827, six Osages came to The City of Light to visit the authorities and claim at the French Court their people's problems, up there before it came to be Canada.

They were victims to some Delaunay's cunning (he exploited their presence as a show) and ended being an object of curiosity by the Parisian public, therefore becoming a precedent for François de Curel idea to take the Charrúas to Paris.

Key words: last Charrúas; otherness; Paul Rivet; François de Curel; Prosper Mérimée.

La descripción de la alteridad revela de manera ineludible la percepción de la propia sociedad de quien describe. Es así que F. Hartog (1980) demostró cómo los escitas constituyeron un verdadero espejo para los griegos, en particular para Herodoto que al describirlos fue forjando una de las bases de la representación de los bárbaros que se difundiera en todo occidente. En Uruguay, quien se vería atribuir esa representación sería el grupo étnico Charrúa, o, para ser más preciso, la "macro-etnia Charrúa", que, siguiendo al concepto de gran complejo charrúa de Eugenio Petit Muñoz (1968), y sin entrar en polémicas recientes sobre los etnónimos apropiados a las poblaciones en cuestión (Bracco, 2004), incluiría a todos los grupos nómades y cazadores-recolectores que resistirían al invasor europeo durante el período colonial, y que serían políticamente eliminados, al igual que en la mayoría de los países americanos con el advenimiento de la independencia (Favre, 1996). Ya es conocida la historia de los denominados "últimos Charrúas" descrita por Paul Rivet, cuya trayectoria hemos podido describir 98 aportando algún dato nuevo en un artículo precedente (Arce Asenjo, 2007). En el marco de este avance presentaremos fragmentos de algunas fuentes inéditas en Uruguay que utilizaremos para enfocarnos en la manera en la que fue descripta su exhibición en París y cómo ésta serviría de pretexto (Bouysse-Cassagne, 1984) para emitir opiniones sobre la sociedad francesa de entonces. Este avance es parte de una investigación cuyo resultado debería ser la publicación de una versión reactualizada del trabajo de Paul Rivet, aún inédito en Francia.

Desde el punto de vista histórico, la triste odisea de los llamados "últimos Charrúas" nos fue relatada a partir, de manera casi exclusiva, desde las fuentes que recopiló Paul Rivet en su "memoria" publicada por la Sociedad de Amigos de la Arqueología en Uruguay en 1930, junto a las publicaciones de Eduardo Acosta y Lara (1961), J.J. Figueira (1977), Pi Hugarte (1969) y Daniel Vidart (1996). Sobre el enfoque particular que nos proponemos en este texto, podemos citar los trabajos de Duviols (2006) y el ya citado Hartog. Sobre la construcción de la imagen del Charrúa en Uruguay citemos los trabajos de A. Houot (2007) y la tesis doctoral defendida, en prensa, del autor de este texto ${ }^{1}$.

La presencia de los 4 Charrúas en París no pasó desapercibida. Es cierto que pocos años antes, en 1827, seis Osages habían llegado a la Ciudad-Luz para visitar a las autoridades y reclamar ante la corte francesa la situación de su pueblo en lo que no era todavía Canadá. Víctimas de la astucia de un tal Delaunay, que explotó su presencia, habían terminado transformándose en objeto de curiosidad para el público parisino y constituyeron de esa forma un precedente para la iniciativa de François de Curel. Este militar francés, que había dejado Francia tras perder su rango en el ejército, procuraba

1. Consultable en la dirección https://tel.archives-ouvertes.fr/tel-00967022/document 
sobretodo recuperar algo de prestigio al llevar cuatro Charrúas ante la corte real y las distintas academias parisinas. Pero rápidamente, a partir del 10 de junio, como lo demuestran los avisos y los artículos en los diarios, empezó a lucrar con su exhibición. El hecho es que el espectáculo tuvo bastante éxito, y que su influencia se puede comprobar a través de la aparición de los charrúas en varios textos por muchos años. Es así que en 1869, Prosper Merimée citó en su última novela Lokis, una curiosa y fantástica costumbre charrúa, la de beber sangre de caballo. Doce años antes, en 1857, en su novela Seul, X.B. Saintine inventó un cacique Charrúa llamado Zimpoll, y describió en un capítulo la visita

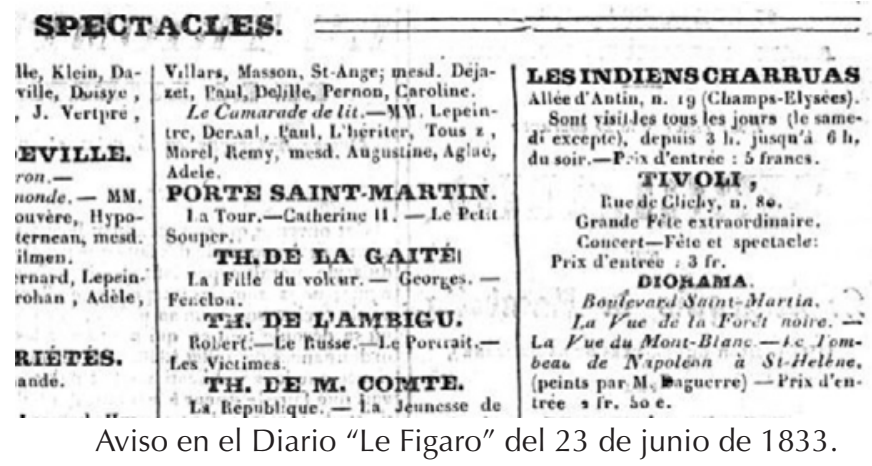

que él hizo a los charrúas en París. Indignado, escribió entonces: “es por eso que en mi último capítulo no pude escribir la palabra charrúa sin que se me enrojeciera la frente" (p. 178). En 1897, un artículo sobre Uruguay publicado por Le Petit Parisien recordó la exhibición, agregando algo que contrastaba con la idea de sus ancestros que se hacía entonces del "Crisol de razas":

"Por codicia cruel, a la Barnuna (sic) se vendieron cuatro a un empresario de circo feriante que los vino a exhibir a Francia y el último de esos hercúleos charrúas murió en un hospital de París. Son los ascendientes de los uruguayos de hoy. Estos descienden de las hijas o de las mujeres de esos indios y de soldados españoles. Y todavia hay escépticos para negar las leyes morales y fisicas del legado hereditario ${ }^{3}$."

De los artículos contemporáneos a la exhibición, conocemos aquellos reproducidos por Paul Rivet, entre los cuales se destaca quizás el de Léon Gozlán en Le Musée des Familles publicado el 31 de octubre de 1833. Este texto constituye una crítica acérrima de la actitud académica y termina con estas palabras:

“(Tacuabé) estudia la lengua francesa; y cuando la poseerá al mismo nivel que el Sr. Virey, en poco tiempo, hará su informe sobre las cuatro academias y los doce académicos: será curioso, le dedicaremos un artículot."

2. Seguramente el autor designa aquí al empresario norteamericano Phineas Taylor Barnum (1810 -1891), recordado por sus célebres engaños en el mundo del entretenimiento y por haber fundado el Barnum \& Bailey Circus.

3. Le Petit Parisien del 23 de abril de 1897.

4. Le Musée des Familles del 31 de octubre de 1833. 
Lo que no sabíamos hasta hoy es que varios meses antes, el 22 de junio de 1833 , un periodista de Le Figaro, que quizás fuera el mismo León Gozlan ${ }^{5}$, ya se había dedicado al ejercicio, redactando un supuesto informe, no con la pluma de Tacuabé, sino la de Vaimaca:

\section{"LES CHARRÚAS \\ Champs Élysées - Allée d'Antin n. 19}

Una comisión compuesta por académicos fue a visitar a los Charrúas con el fin de realizar un informe sobre estos interesantes extranjeros: por un extraño contragolpe, el jefe de los Charrúas hizo por su lado un informe detallado sobre esos visitantes: solo hemos podido conseguir esta parte preciosa cuyo autor quiere algún día compartir con sus compatriotas.

Hemos colocado entre paréntesis algunas explicaciones sobre objetos o personas que Vaïmaca-Pérou (sic) no pudo caracterizar sino muy aproximadamente en una primera inspección.

"Yo, Vaïmaca-Pérou, jefe de los Pampas del Uruguay, Río-Negro, del Ibicuy, y de todos los lugares bañados por la Urana (sic), venido en Francia con Senaqué, llamado el médico,Tacuabé, joven guerrero, Guyanusa (sic), mujer, esposa y madre, declara haber observado los siguientes rasgos de carácter en las personas blancas, el día en que veinte de esas personas vinieron para honrar nuestra morada."

(Los veinte miembros del Instituto, secciones moral y científica, reunidos para confeccionar un informe sobre los Charrúas.)

\section{INFORME DE VAIMACA-PEROU, CACIQUE}

Un hombre pequeño, con un sombrero blanco, cosa rara por tener ya la piel blanca, cubierto de escamas en forma de cola de pájaro (traje marrón), teniendo las piernas cubiertas de pelusa negra, como las cacatúas (pantalón negro acampanado), llevando una piel de tiburón seca bajo los pies (botas de 18 francos). Este pequeño hombre (académico, sección moral del Instituto) no me dijo nada: por lo que concluyo que es mudo, y por lo tanto que pronunció demasiadas veces tonterías en su vida. Se le arrancó la lengua, y se le dejó su sombrero blanco. Este hombre es lo que llamamos en nuestra lengua un Topinamboux ( $\mathrm{sic}$ ) degenerado. Como le he visto llevar a menudo la mano hacia su nariz, supongo que no le gusta el olor del sebo agriado, lo más perfecto después de la carne de vaca podrida. Este hombre es por lo tanto mudo y enfermo. Lo compadezco y lo culpo, yo, Vaïmaca-Pérou."

"He observado aún, mientras estaba acostado sobre mi piel de perro y mi piel de rata, otra piel blanca que no pertenecía ni a un perro ni a una rata; era la de un jefe de tribu blanca. Lo adiviné por el bastón que llevaba en mano, ya que no lo usaba para sostenerse (mimbre de Thomassin), pero a manera de cetro (miembro del Instituto, sección mecánica). Me tomó el pie, o debería mejor decir que le di la mano con mi pie. Dijo, después de su operación, o de la mía, pie plano, palabra que en nuestra lengua, hermosa, rica, magnífica, significa: Es un guerrero fuerte y generoso. Entonces con mi

5. León Gozlan empezó a escribir en Le Figaro en 1830. 
pie le apreté la mano, y le agradecí de haberme llamado pie plano (pied-plat-piewplaah, guerrero fuerte en idioma Charrúa).

"El jefe de tribu habiéndose despedido, vino hacia mí un guerrero, un Tacuabé blanco, hombre de combates. Adiviné eso por su instinto, sus costumbres de cortar el cuero cabelludo de la cabeza de los enemigos matados. Me agarró la cabeza entre sus diez dedos, la midió con un cordel para saber cuánta agua podría contener una vez que se le hubieran quitado los cabellos, y le devolví la atención. Si llego a ser yo quien lo mate, pienso transformar su cráneo en tabaquera. Nos prometimos eso mutuamente. Este guerrero (miembro del Instituto, anatomista) me dio una medalla en la que está su retrato (una moneda de veinte sous); me servirá para obtener aguardiente.

"Guyanusa está triste. Aunque infinitamente más linda que una linda mujer de color de coco (una morocha), y que una mujer aun más linda color de abeja de Pavana (una rubia), que habían venido ahí con los guerreros, los jefes de tribus y los caciques del país pálido, Guyanusa, la bella Guyanusa, con olor de sebo, con las axilas grasientas, con labios de caballo, ojos que se cruzan por la punta como dos flechas, se puso celosa de esas dos mujeres; lloró, temió por el corazón de Tacuabé, Tacuabé el dormido, el bisonte, el búfalo, que muge de amor, y que tiene la piel de color de poroto rojo. Pensó que Tacuabé que se hizo el lindo, que caminó cuatro pasos para esas mujeres, que lanzó su lazo contra un poste, su flecha contra una tabla, iba a abandonarla como la flecha y el lazo. Desde ese instante, no quiso consumir ni vaca podrida de tres días, ni caballo mortificado al sol desde ocho soles. Lo endulzaremos con perro en plena degradación.

"Senaqué, el doctor de los doctores se muere, y eso por nada, por una lanza de seis pulgadas en la boca del estómago. Que muera rápido si debe morir, ya que está endiabladamente flaco, y no veo demasiado lo que nos dejará de comer, por poco que adelgace todavía. No es un amigo.

"Dentro de los jefes de tribus que nos visitaron, parecería que ninguno es médico, fuera de Senaqué, ya que no dieron a nuestro Senaqué ni queja para curarse, ni talismán para salvarlo. ¿No habrá por lo tanto un Senaqué en el país de los pálidos? El que le tocó el brazo (le tomó el pulso), hombre joven y sedoso (famoso médico de París), se rió mucho del sombrero de Senaqué: reir no es curar.

"Esto fue lo que recaudé mientras todos esos hombres nos miraban en silencio y parecían no habernos visto nunca, a nosotros, los primeros pueblos del mundo, los más grandes, los más gloriosos, los más valientes, los más generosos, los más magníficos, los más libres."

Firmado: VAÏMACA-PÉROU

SENAQUÉ, llamado el médico

TACUABÉ, joven guerrero

GUYANUSA, mujer.

Como podemos verlo, la inversión permite al autor criticar a los académicos, de los que ridiculiza el conocimiento, tal como en el artículo del Musée des Familles, lo que nos invita a pensar con más fuerza que ambos fueran obra del mismo autor.

Días antes encontramos otro artículo que tampoco fuera publicado por Rivet, y que esta vez pondría su descripción de la exhibición de los charrúas al servicio de una crítica del mundo teatral parisino. Intitulado "Los salvajes y las flores" y publicado en el Journal des Débats Politiques et Littéraires el 10 de junio de 1833, fue firmado nada menos que por Jules Janin (1804-1874), escritor y crítico teatral y literario, apodado "el príncipe de los críticos", y que sería electo miembro de la Academia Francesa el 7 de abril de 1870: 
"El drama bastardo nos dio descanso toda esta semana. La ópera cómica se mantuvo callada en sus bosques. El vaudeville se fue a pasear quien sabe dónde, a caballo o a lomo de burro. Yo, viví como un verdadero burgués ocioso y vagabundo; fui feliz en toda comodidad esta semana, y también he sido bien recompensado por mi pena el último día; vi las más lindas flores del mundo en las Tuileries, los más espantosos salvajes indios, en los Campos Elíseos, recostados sobre pieles de animales, al sol.

Hace tiempo que lo he dicho, no hay que preocuparse por el futuro del drama, el drama no nos hará nunca falta. El drama no está en el teatro, es cierto; pero, fuera del teatro, está en todas partes, si entiende por esa palabra drama, esa emoción mezclada con asombro e interés sin cansancio, que se encontraba en el antiguo teatro. Vio eso sobre nuestras paredes todavía y siempre. Apenas el teatro mantiene silencio que la historia se pone a hablar en voz alta. Una revolución imprevista sustituye a menudo una tragedia ausente. No tiene drama esta semana, llegan los Osages, llega el dey (sic) de Argel; llega don Pedro, o cualquier otra majestad destronada para ocupar el escenario del mundo. La verdad se sustituye a la ficción, ausente. El héroe histórico se pavonea en lugar de los héroes imaginarios. Esta semana no tuvieron ni siquiera un pequeño drama; ¡y bueno! aquí viene el Cacique de la tribu de los Charrúas, acompañado por su médico y su guardaespaldas. El Sr. Scribe no hizo vodevil para la Señorita JennyVertpré, ¡y bueno! He aquí que viene la bella Guyunuya, otrora mujer querida del Cacique Vaimaca, hoy, lo sospecho, simple amante del guerrero Senaqué; finalmente, a falta de opera cómica del Sr. Planard, encontrará en la naranjería de las Tuileries, donde la Sociedad de horticultura de París hace su exposición pública, una exposición entera de flores.

Empecemos por la gran obra, como siempre se hace. Vamos a ver a los Salvajes. Vengan. Están alojados en los Campos Elíseos, en una de esas casas a mitad edificadas que la falta de dinero ha detenido en su progresión; ruinas de hoy, ruinas nuevitas, cuya visión es triste sin ser solemne. Los héroes de nuestro drama están alojados allí. Vinieron del fondo de América Meridional para agacharse bajo el débil sol de París. Vengan a verlos. Son hermosos actores. No son más altos que nuestros héroes del Teatro Francés, es cierto, que nuestros Agamenones y nuestros más bellos Alejandros; pero son ricamente compuestos. Son ágiles, buenos jinetes, intrépidos domadores de caballos salvajes; son pérfidos, perezosos, vengativos, crueles, algunos son hasta antropófagos; tanto que nada les hace falta para ser muy buenos comediantes modernos. Efectivamente, saben hacer todo lo que le pide hacer a los comediantes en el drama moderno; saben galopear, pelear con sable, traicionar, vengarse, asesinar, comer carne cruda. Es cierto que no conocen una sola palabra de francés; pero es un motivo aún mayor para que obtengan un gran éxito por el drama que se produce todos los días.

Cuando los vi agachados en un patio amplio, reconozco que francamente me creí ante la exposición de alguna tragedia moderna. Los valientes salvajes llevaban un vestido raro y espantoso; estaban sentados los tres en posiciones diferentes y solemnes. Uno de ellos era el Cacique, con sus dos rodillas dobladas, las manos unidas, las tetas colgando, gordo y robusto y corto tirano de la edad media, con un aire espeso y majestuoso, el cabello mal peinado, se parecía increíblemente, a algún bandido bonachón de un melodrama de M. Caignez; el otro, delgado y flaco, pálido, afinado, encorvado, doblado, enrollado en todos los sentidos, salvaje astuto con la mirada oblicua e indefinida, me recordaba mucho al Bas de cuir de Cooper, del que tiene el cráneo y la actitud; el tercero, vivaracho, alegre, despreocupado, vagabundo, verdadero caballero en manto de piel, acostado indolente y cómodo en el piso, se parecía en algo a un héroe 
barbudo y espiritual de los melodramas del Sr. Alejandro Dumas, a un Antony de la tribu de los Charrúas; con más razón por haber sido él, el CharrúaTacuabé que le quitó al gran Cacique Vaimaca, apodado Peru, su mujer, la princesa Guyunuya, su mujer legítima. Por lo tanto Antony-Tacuabé se relaja al sol, meditando sin duda la vanidad de las legislaciones humanas, sobre la desgracia de ser bastardo y las inconsecuencias del Código Civil de los Charrúas.

Y en el fondo del patio, tímida, reservada, decente, ocultando su rostro en su pecho, Guyunuya, agobiada por el sentimiento de su cautividad, como lo pudo estar otrora una princesa del Ilión destruido. La Sra Dorval en persona no logra tener una actitud más consternada, una desesperación más real y más simple que ella. Todos los personajes de nuestro drama están por lo tanto reunidos; drama totalmente burgués aunque salvaje; drama totalmente de moda en el que una sola mujer alcanza para la pasión de todos esos hombres; drama totalmente moderno, en el que encontrarán la eterna lucha del joven y del viejo, del soltero y del hombre casado, de la sociedad y de la naturaleza; drama completo, por otra parte, y perfectamente concebido siguiendo las reglas, ya que se puede ver a un avestruz vivo, a los héroes cocinar su carne de caballo para comerla totalmente cruda (sic); ya que se fuma tabaco, que se toma, que se hace el amor, que casi no se habla francés. Vayan a ver a nuestros salvajes y verán si realmente vale la pena hacer nuevos dramas.

No, realmente, no vale la pena; ya que hemos llegado a satisfacernos del espectáculo para los ojos y los oídos, ya que tomamos como verdad dramática esta reproducción literal de las cosas reales, y no como otrora la imitación elegante y apasionada de los instintos, de las necesidades, de los odios, de los amores y de las creencias de la humanidad en lo que tiene de elevado, de ingenioso y de poderoso. No podíamos tener nada mejor, incluso después del elefante, incluso después de los leones, los osos, los tigres y las panteras de Martin y demás héroes dramáticos que los cuatro salvajes hombres y mujer de la tribu de los Charrúas.

$\mathrm{Y}$, se los ruego, no digan aquí que me entrego a una exageración de mal gusto. No, no es una exageración. Dígame, se lo ruego ¿qué hacen esos salvajes en su corral que no hayan hecho nuestros héroes de teatro? He aquí un Cacique, tomado de aguardiente, que vive felizmente sobre las ruinas de su trono, guerrero valiente y mutilado, que se muestra en un espectáculo por un trozo de caballo cada día; este, por más grande que fuera en su tribu, por más mutilado que fuera, ¿será más grande y mutilado que el emperador Napoleón, puesto en venta por ustedes otros dramaturgos por un trozo de caballo? Este joven muchacho desnudo, con apetito desordenado, con pasiones impetuosas, excesivamente enamorado, excesivamente borracho, ¿está más desbocado en su pasión que esas pequeñas personas que secuestran mujeres, que degüellan hombres, que actúan y toman de la mañana a la noche? No, ciertamente que no. ¡Y es más aún, mi héroe salvaje, por más goloso, descontrolado, desaliñado que los suyos, tiene la gran ventaja de no soltar chatas máximas sentimentales y pésimos lugares comunes de política y de virtud! Y el traidor de la banda, ese que ven rastrillar la madera con su lengua, perforar el hierro con sus dientes, duro en su labor. Perseverante, escéptico y burlón como si hubiera leído Voltaire, ¿no será un traidor a su manera, y no se hallaría feliz de haber encontrado ese héroe, a la vez fabricante de flechas y cirujano, médico y guerrero, un verdadero tipo que solo se encuentra en la Ilíada?

En cuanto a la mujer de esta tribu, es sublime. Tiene todos los vicios de sus mujeres dramáticas, es cierto. Como sus heroínas es coqueta, fácil, le gusta el placer, es viajera, no le teme a las aventuras, tiene pocas ideas sobre la fidelidad conyugal; pero más que 
sus heroínas, tiene pasión y amor, y sobre todo tiene dolor. Esta mujer me emocionó mucho a mí que le hablo. Con gran pena tomé sus brazos en mis manos; y en sus brazos, ¡Dios que marcas sangrientas! ¡Qué cortes profundos! En cada suceso triste de su triste vida, esta mujer se mutiló a sí misma. Cada uno de esos dolorosos surcos sobre su carne es la historia de un dolor. Se hizo un tajo por cada uno de sus amigos fallecidos. Se cortó un dedo por cada niño que perdió; tiene ya dos dedos menos. Ya tiene de sesenta a ochenta marcas sobre el brazo; ; es que ya tiene dieciocho años! Con un poco de atención notará en los brazos de la Hécuba salvaje, y entre los tajos profundos, unos rasguños livianos casi borrados; me imagino que esos rasguños forman la historia de sus penas de amor, penas fugitivas, dolores de un día! Es el golpe de alfiler al lado de la puñalada, es la página de fuego de Bossuet al lado de la hoja de rosa de Marivaux.

¿Tendrá usted, en sus dramas, una mujer como esa? ¿Tendrá dolores tan profundos en todas sus poesías? ¿Sabrá darle a sus héroes la fisionomía y la expresión de estos héroes? ¡Dice que sus héroes son valientes! ¡Pero he aquí uno que tiene el hombro partido por un hachazo! ¡Dice que son celosos! ¡Pero he aquí uno que por una francesa blanca, la última blanca que chilla en sus coros o que baila tristemente en un rincón de su ballet, va a desafiar cuerpo a cuerpo doce caballeros del bosque de Boulogne! ¿Dice que sus héroes son malos, crueles, degolladores? He aquí uno que fabrica flechas y que las envenena con su saliva! ¿Dice que sus mujeres son sensibles? He aquí una que se cava el brazo con un feo cuchillo con la misma calma con la que una de sus mujeres agitarían un abanico. ¡Pobres dramaturgos! ¡Pobres efectivamente y vencidos por los recién llegados desde las llanuras del Uraguay (sic) ! Es que una vez que dejamos el drama poético por el drama del corazón, la verdad literaria por la verdad vulgar, se

104 debe uno esperar a verse derrotado por cualquier uno que llegue, salvaje o no, que es el más desaliñado y el más agachado; sin embargo es imposible ser más desaliñado, más agachado, más negro, más sin pudor, más sin creencia, más dramático finalmente que los tres salvajes de la tribu de los Charrúas.

No hay mucha distancia entre la comida de los salvajes, ese atroz pedazo de carne cruda y negra, que cuelga oblicuamente sobre un espetón durante algunos minutos, y que se desgarran entre ellos sentados alrededor del espetón, y lo que ha sido hecho en nuestros teatros. Hemos visto en la Gaîté, Hand Islande comiendo carne cruda y bebiendo en un cráneo. Hemos visto casi eso en la Porte Saint-Martin.

Incluso sobre ese tema hice una observación en el cuarto de la bella Guyunuya.

Ese cuarto, (¿podremos llamarle cuarto?) está posado en la extremidad de una escalera. Es en su totalidad un simple techo abierto a todo viento. Debajo de ese techo se tiró un colchón que es todo el mobiliario. Esos salvajes tendrán una pésima idea de nuestra civilización en los apartamentos que les damos. Efectivamente, la única huella de civilización que haya visto en su cuarto, es ¿podrá creerlo? un afiche de espectáculo, pegado en la pared junto a varios otros. Sobre uno de esos afiches se lee en letras grandes el nombre de otro famoso comedor de carne cruda: Shilock.

El pequeño salvaje no entendía para nada mi asombro.

Y para que pueda comprobar todo esto, esos hombres desnudos, esta mujer abandonada a sí misma, esas heridas, esas flechas, esa comida alrededor de un espetón sangriento, que todo eso no es el drama, tienen que saber que no les faltó la historia misma, a esos hombres para ser dramáticos. Solo la poesía les faltó, ya que por sí mismos son lo más dramático que se pueda ser; son tan poéticos cuanto los héroes de Homero. Vaimaca-Peru es realmente un jefe de tribu, un cacique verdadero, una total realeza vagabunda que no tiene por qué descubrir su cabeza más que todas las demás realezas 
del mundo. Senaqué es realmente, el amigo devoto del cacique, su sujeto fiel y triste, más triste y solemne que el mismo rey destronado, como pasa a menudo alrededor de los tronos rotos. El otro es ese joven muchacho despreocupado y valiente, vencido y aún alegre, poco inquieto por una causa perdida porque es joven y cree en el futuro; la mujer Guyunuya es la verdadera mujer épica sometida al destino, cuya mismísima risa está llena de lágrimas, y que se consuela de sus desgracias por sus debilidades. ¡Saben ustedes que vienen del fondo de Sudamérica! ¿Saben ustedes que vinieron aquí, a París, como a un Champ d'asile, y que éste es el peñasco de Saint-Helène para el Cacique ${ }^{6}$ ? Todavía se habla de sus batallas y de su valentía. Han combatido mucho tiempo contra Ribeca (sic). Hace un año, su tribu entera fue destruida. Huyeron al desierto, llevándose, no su harpa como el Hebreo, pero los cráneos de sus enemigos, ornamentos de sus cabañas. Y ahora, vencidos, fugitivos, presos, llegan de tan lejos para recibir la visita del Sr. Geoffroy Saint-Hilaire (sic), el aficionado a los monstruos. El Sr. Geoffroy Saint-Hilaire, la última palabra de toda biografía, el último juez de toda la humanidad, ese hombre aparte y de un cráneo aparte, quizás mayor filósofo de lo que se piensa y que lo cree él mismo, y que resolvió todo el problema de la historia natural, con esta palabra, sin ningún sentido y muy exacta : iii monstruosidad!!!

Y después de los sabios inútiles, esta cosa tan común como lo son los poetas insignificantes, vino el frenólogo Sr. Dumoutier, el mismo que reconoció, sin haberla visto jamás, a la vieja mujer asesinada y enterrada desde hace diez años en el jardín de la calle de Vaugirard. El Sr. Dumoutier tomó la cabeza de los salvajes, y con su imperturbable sangre fría asignó a cada uno de ellos sus capacidades, sus afectos, sus odios. Dijo que eran desdeñosos de la vida, crueles, olvidadizos del tiempo, propensos al amor, poco melancólicos por naturaleza, poco dedicados y muy valientes; era suficiente como para provocar la envidia de hombres verdaderos. Para mí, al ver esos pobres hombres bajo la mano del profesor en frenología, explicados, comentados, analizados a pesar de su voluntad, como se haría con un animal mudo, no pude defenderme de una gran tristeza. ¡Son hombres! ¡Son por lo tanto hermanos nuestros! Les debemos amistad, estima y respeto como a nuestros semejantes. Su cuna tiene derecho a nuestro cuidado, y su ataúd a nuestras plegarias. ¡Hay ahí suficiente como para confundir unas cuantas vanidades! Ya que son sin duda alguna hombres; ¡escúchenlos hablar y véanlos sonreír! Y si no entienden ni su lengua ni su sonrisa; ¡ Ustedes se lo pierden!

¡Cómo han cambiado los tiempos! Otrora, cuando el reino de Francia era cristiano, la llegada de esos salvajes, vestigio fugitivo de su tribu, habría agitado todo el catolicismo parisino. Nos habríamos preocupado para empezar por su alma inmortal. Habrían encontrado en la amante del rey una madrina, y en algún príncipe de sangre un padrino; habrían sido objeto infinito de disertaciones filosóficas y religiosas; jansenistas y jesuitas se habrían disputado esas cuatro almas con una obstinación totalmente teológica; ellos, no obstante, habrían aprovechado a su manera esa ansia de toda la sociedad cristiana; habrían inclinado su cabeza bajo las aguas del bautismo, lo que valía tanto como inclinarla bajo la mano materialista de los discípulos de Gall, y habrían vuelto a su tribu, cubiertos de bienes, llenos de honores, festejados, cantados, celebrados y bautizados.

Los salvajes han por lo tanto perdido mucho con la abolición de la fe católica en Francia. Ya tan solo son simples objetos de curiosidad frívola; eran otrora nobles

6. El Champ d'asile fue una colonia francesa efímera, fundada en el actual Estado norteamericano de Texas en 1819, por 120 oficiales bonapartistas. El autor contrapone ese lugar con la isla de Saint Helène, en la que moriría Napoleón Bonaparte en 1821. 
conquistas que el Cielo mismo envidiaba. ¡Y había que ver, ahora, cuanto aislamiento alrededor de ellos! ¡Qué profunda soledad! ¡Cuántas vagas miradas de piedad y de interés! ¡Cuántas preguntas miserables! ¿Y qué se han vuelto esos pobres grandes señores del desierto? A su llegada a Francia, son recibidos por la Academia de Ciencias, encabezada por el Sr. Geoffroy Saint-Hilaire; van de ahí a Saint-Cloud o Neuilly, si lo permite el maestro de ceremonia; después de lo que el director de la Ópera les facilitará quizás un palco el día en que se dará Nathalie sin la SrtaTaglioni; irán de la Ópera a la Porte Saint-Martin, y después al Circo Olímpico, y después a algún cabaret bailable de última categoría, donde serán apenas mirados por la plebe dominguera que prefiere una contradanza a todos los salvajes del universo ; afortunados aún si no es que, como sus hermanos del Norte, los Osages, ¡nuestros indios del Sur no mueren en el hospital entre dos hermanas de la caridad!

Sin embargo, aquí encontramos una de las mayores similitudes entre la vida de nuestros indios y el drama moderno. Nuestros indios son sin creencia, sin instinto religioso; actúan y se mueven al azar o siguiendo sus pasiones; están perfectamente desprovistos de toda idea moral; están sometidos a la fatalidad toda su vida: basta con verlos agachados sobre sus pieles de animales, los ojos semi-cerrados, ocupados en vivir y dormitar, sin darse la pena de soñar; los confundiríamos con plantas grasientas, aceitosas e infectas, que vegetan sobre el estiércol. Lastima la vista, si uno se pone a pensarlo.

Y sin embargo, no podemos impedirnos tener por esos hombres toda la benevolencia que un alma bien hecha dedica a sus semejantes; por eso fue que, al irme, les he dado la mano tan cordialmente como me fue posible hacerlo. Me devolvieron mi apretón de manos, y me dijeron: ¡Adiós, señor!

No olvidé tampoco acariciar al avestruz que galopea en el patio, despreocupada y alegre y golosa como en el desierto, linda como en el desierto; ya que uno de los privilegios del animal es el de ser más inteligente y más bello, así como el hombre se vuelve más estúpido y más feo, al acercarse al sol. Este pájaro es muy amable. Como no tenía nada para darle, le ofrecí una moneda que supo aceptar, y que se tragó en el buche con la gracia de un hombre civilizado.

Al salir de allí experimentará no sé qué indefinible serenidad. De hecho, se encuentra entre los hombres; deja el África (sic) por Francia, el desierto por París; acaba de escapar a esos hombres cobrizos, tan feroces, tan sanguinarios, tan despóticos, tan crueles. Estaba bajo su dominio hace un rato, sometido a su fuerza brutal, ocupado en servirles, siendo su esclavo y el de sus niños. Al salir de ahí, entra bajo una ley común a todos; es igual a todo el mundo, los más grandes y los más débiles; está en una sociedad bien regulada y bien hecha, inteligente, activa, laboriosa, humana, respetable, respetada, feliz, poética a veces. Una gran admiración le cautiva por todo lo que le atañe. Vuelve a colocar con orgullo su sombrero sobre su cabeza; mira con admiración la ropa blanca que se puso en la mañana; está orgulloso del guante que viste su mano y está dispuesto a caer de rodillas ante vuestro reloj que le indica la hora. Se lo repito, es un viaje que debe hacer, un drama que tiene que ser visto. Solo que si su caballo lo lleva a la vuelta, no le aconsejo sentirse orgulloso por ello, porque el último hombre de esta tribu, desnudo, sin silla, sin espuelas, casi sin mordazas, va a domar en diez minutos el más indomable de los caballos. ¡Pero bueno ¡ Algo hay que dejarle al desierto, París no lo puede tener todo. (...)

Era ahí un gran contraste. ¡Caer de la barbarie aceitosa y carnívora de América a la civilización más almizclera de París! (...)” 
Este artículo (traducido aquí casi integralmente) parte de la oposición entre la fealdad del espectáculo que ofrecen los charrúas y la belleza de las flores mostradas en las Tuileries, lo que explica la última frase. El autor usa la analogía con el mundo teatral parisino para criticar la calidad de este último, pero también para reflexionar sobre la realidad y su representación. El tratamiento reservado a los Charrúas es también objeto de crítica, y es asociado a la actitud de los científicos. El apodado príncipe de los criticos, también aprovecha la ocasión para reivindicar la preocupación evangelizadora de la fe católica frente a la curiosidad de los académicos y del público. Y esto le sirve de moraleja, ya que es precisamente al abandono de la fe que el autor atribuye la principal coincidencia entre el drama teatral y esta exhibición humana.

Un mes más tarde, el 15 de julio de 1833, encontramos en el periódico Le Voleur, en el que escribiría nada más ni nada menos que Honoré de Balzac, otro artículo suponemos también desconocido por Paul Rivet. Firmado con las iniciales F.G., lleva el título: "Diletantismo de los Charrúas."

"Organice un pequeño cuerpo de ejército, compuesto por naturalistas, filósofos, académicos, artistas famosos, agrúpelos contra cuatro pobres Charrúas en un corral inculto, estrecho, lleno de espinas, quizás para que el terreno sea igual para las dos partes y que la civilización no tenga sus fortificaciones, lo que sería totalmente injusto. Escuche a los naturalistas disertar sobre las inclinaciones de la raza americana pura, sobre la forma de esos cráneos que se prestan durante dos segundos con aburrimiento y se retiran con un movimiento de humor borrado rápidamente. Espíe las impresiones sobre esas fisionomías primordiales.

¡Cuidado! El aire va a palpitar con los acentos de una melodía sucesivamente tierna, apasionada, soñadora, enérgica: van a ver a esos hijos directos de la naturaleza, a esas revelaciones de la espontaneidad humana. Escuchen, miren; mírenlos escuchar, escúchelos mirar... la melodía vibró... espectáculo increíble...

Conocen señores, la historia de ese inglés que al haber encontrado en Italia un soberbio eco, que repetía siete veces un estampido de pistola tirado desde la ventana de un castillo en ruinas, quiso enriquecer su parque con éste. El inglés hizo venir a un arquitecto, a un agrimensor, a un físico; se estudió escrupulosamente la distribución de los lugares. La casona fue demolida, las piedras numeradas, empaquetadas, expedidas a Inglaterra, y lo fueron también el agrimensor, el arquitecto y el físico. El lord (porque se trataba de un lord) eligió en su parque un sitio totalmente análogo al del eco italiano; ¡admire la dicha de circunstancias! Un pequeño bosque a la derecha, como en Italia: una colina transversal a trescientas toesas como en Italia, un pequeño lago a la izquierda, también como en Italia. Cuando la casona se vuelve a levantar, con el eco ajustado, el sitio italiano repetido minuciosamente, nuestro lord invita a la mejor sociedad del condado a la inauguración del fenómeno: se cena bien, se toman siete vinos diferentes en siete momentos diferentes, como delicada alusión al eco futuro. La sociedad, después del postre, sube a la sala desde donde se debía disparar la pistola. Los curiosos de la región estaban agrupados por todos lados, en multitudes y de una forma pintoresca. El corazón del lord latió un instante, pero tranquilizado por los cálculos reunidos por tanto sabio pagado tan caro, arma la pistola, pasa su brazo por la ventana, dispara. La detonación se escucha maravillosamente, pero después, nada... De pura vergüenza, mi inglés toma otra pistola y se quema el cerebro.

Si hubiese hecho lo mismo, señoras y señores, no les contaría en este momento la mistificación que la especie humana civilizada padeció ese día por la especie humana primitiva. El personal Charrúa está compuesto por un cacique de unos cincuenta años, de 
un joven muchacho que no conoce su edad como los demás, pero al que le doy 20 años; de una mujer un poco mayor que él, y de un pobre diablo ya arrugado, muy enfermo, muy triste, muy flaco, muy resignado (cualidad que las otras vuelven muy necesaria).

El cacique tiene algo noble en su despreocupación, e imponente en su estupidez; el joven muchacho parece dispuesto a la alegría, la muchacha también; bueno, decía bajito, he aquí el tipo de Chactas ${ }^{7}$; ¡cuántas emociones en ese corazón de salvaje, cuánta sabia, cuánta poesía! En esa fisionomía de mujer se ve la expresión de cada sentimiento, pronta a surgir, la expresión de cada sentimiento, el amor, la ira, la alegría, la preocupación, el capricho; su esposo tiene esa confianza, esa presunción, ese dandysmo que tiene la juventud en todas partes, bajo cualquier forma. Otros sufren; a toda esa gente le debe gustar la música. ¡Qué fiesta! Asistir a las primeras impresiones musicales del último de los Mohicanos... no, de los Charrúas: ¿qué corazón puede estar suficientemente hastiado como para no encontrarse emocionado tal si viera las sabanas y las selvas vírgenes del Nuevo Mundo? Su alma se va a derretir, van a llorar, quizás a saltar de furia; hacer música delante de ellos, música instrumental ejecutada por los Sres. Tulou, Meifred, Jacqmin, Bailly, Beauverné, Dufresne y otros artistas de primer nivel. Sería prudente entregar a los Charrúas tantas sensaciones sin moderación, sin precaución? Los músicos se han escondido detrás de una pared, no corren riesgo; pero el Sr. Geoffroy Saint-Hilaire, el Sr. Berton, y el Sr. Sudre, autor de la lengua musical, y algunos otros, nos encontrábamos allí entre los salvajes, recostados sobre sus pieles de animales, y las brasas que habían servido a cocinar su almuerzo. Esas brasas diabólicas y ese fuego mal apagado me invitaban a pensar... Finalmente la sinfonía empieza: dos de los Charrúas giran la cabeza hacia el lado de donde venía el ruido, la vuelven a girar enseguida y dejan de ocuparse de ese murmullo, tal como lo hacían con los disparos de arcabuz que se producían a cada minuto en un campo de tiro cercano.

Conté hasta treinta personas que sudaron la gota gorda para estudiar sensaciones de Charrúas, y cuatro Charrúas que no sudaban para nada, y no parecían aburrirse al ver tantos curiosos. Estupidez total; las flautas volvieron a sus estuches, los cornos con pistón en sus estuches de cuero, los académicos, los curiosos en los coches de punto: la gente se dispersó... perdón, me equivoco, la gente se reunió, y, para consolarse de la desventura, se contaron historietas análogas a la circunstancia.

"¿Cómo quieren, señores, decía uno, que esos interesantes salvajes aprecien nuestra música? Durante la expedición en Egipto, en una fiesta celebrada por la apertura de los canales de riego, árabes y franceses ejecutaban cada uno sucesivamente sinfonías a su manera; a los árabes no les gustaba nuestra música aparte de cuando los instrumentos hacían pruebas y producían sonidos discordantes en forma de guirigay." "¿Eh! Señor, gritó otro. Esa misma aventura nos ocurrió en Grecia" (seguramente Otón no habrá sido el héroe de la fiesta).

"Y el dey de Argel, señores, el dey de Argel es también un curioso diletante, dijo un tercero. Después de un concierto ejecutado para su alteza, se le pidió lo que pensaba de nuestra orquesta. Muy bien, muy bien, contestó el príncipe destronado; pero lo que me sorprendió más que nada, es que ví un señor en un rincón comer cobre durante dos horas sin lastimarse (hablaba de un trombonista)."

7. Chactas es el nombre de un personaje de la novela de François-René de Chateaubriand Atala, publicada por primera vez en 1801 y de gran influencia para la elaboración de la imagen del indio "nacional" Charrúa (Arce Asenjo, 2014, 2015). Chactas es un indígena Natchez, de edad ya avanzada, que adopta al héroe René, un francés que elige vivir con los indígenas. 
Con esas palabras se separó la asamblea: al salir todos parecíamos más o menos Charrúas.

F.G."

Esta vez el autor del artículo burla la iniciativa musical, aportando como nuevos datos la presencia de los señores Meifred, Jacqmin, Bailly, Beauverné, Dufresne y Sudre. A partir de lo que observa, desarrolla una reflexión sobre la relación entre el contexto y el sujeto, entre las pampas uruguayas y los charrúas, lo que muestra a través de la metáfora del eco que no consigue recrear un aristócrata inglés.

El Charivari ${ }^{8}$ es uno de los primeros diarios satíricos del mundo, abiertamente opositor al gobierno de Louis-Philippe, es famoso por las caricaturas de Charles Philippon (1800-1862) que marcaron un antes y un después en la historia del dibujo periodístico, haciendo del dibujante un precursor de lo que más adelante se llamaría comics.
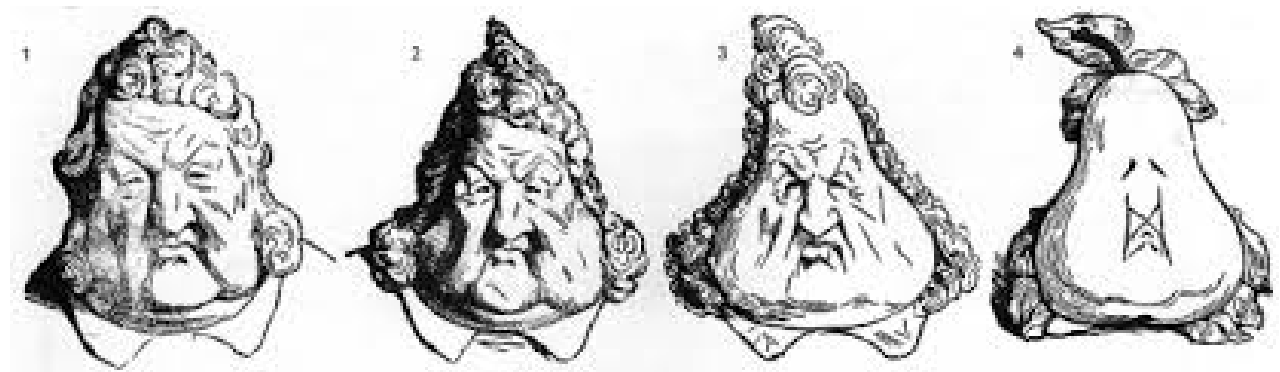

Caricaturas del rey Louis-Philippe metamorfoseado en pera, por Charles Philipon, publicadas por primera vez el 24 de noviembre de 1831 en La Caricature, y en Le Charivari del 17 de enero de 1834.

En la edición del 6 de julio de 1833 ( $\left.n^{\circ} 218\right)$, podemos leer, en la pequeña columna dedicada a la presentación del dibujo que el diario siempre publicaba: "Ofreceremos pronto a nuestros suscriptores el retrato de los Indios Charrúas que fijan en este momento la atención pública, junto con el memorable conflicto del Constitutionnel y del Journal des Débats". Esta promesa es reiterada en la edición del 13 de julio, en la que podemos leer: "publicaremos mañana una caricatura política, y la semana próxima, el retrato de los Charrúas y el Mont Saint-Michel". Lamentablemente, no hemos podido encontrar dicha estampa. Sí veríamos citar a los Charrúas en una "charada" del diario del 8 de julio, dos días más tarde, y sobre todo, el 16 de julio, en un artículo en primera plana, intitulado "Meditaciones filosóficas - Acerca de su Majestad Louis-Philippe $1^{\text {ero }}$ por una parte, y de su Majestad Vaimaca último por otra parte".

"Todos saben que tenemos el placer de poseer, en este momento, en los Campos Elíseos, allée d'Antin n ${ }^{\circ} 19$, cuatro salvajes de la mejor especie:

1 Vaïmaca, más comúnmente conocido por el nombre de Perú, de aproximadamente cincuenta años, diez años menos que Louis-Philippe, rey destronado (hablo del Charrúa) de una de las más florecientes tribus de esa especie.

$2^{\circ}$ Senaqué, uno de sus generales más distinguidos, especie de mariscal de Francia de ese país, que cumplía con su majestad salvaje, las mismas funciones que más o menos cumple el Sr. Athalin con su majestad ciudadana, es decir que era su edecán.

8. El título del diario, Charivari designa un ritual colectivo festivo, muy parecido al carnaval del que se distingue por no respetar una fecha del calendario. 
Ya que, salvajes o civilizados, los reyes han siempre necesitado que se les ayude en los campos; sobre todo los reyes civilizados.

$3^{\circ}$ Tacuabé, joven héroe de 19 años, es del tipo de nuestro príncipe Rosolin; no tan bien educado quizás, ni tan bueno para la danza, la botánica ni la teoría de la guerra; pero que podría tener algo para oponerle a nivel de la práctica. Y eso no tiene nada extraño. La superioridad de heroísmo práctico que puede reivindicar el guerrero salvaje sobre su semejante de las Tuileries, aunque le sea más joven de cuatro años, esa superioridad está basada únicamente sobre la diferencia de los climas en los que cada uno de ellos ha crecido. Los hombres son como los melones y los pepinos: el calor del sol los vuelve singularmente precoces. Transporte un melón, transporte al príncipe Rosolin en los desiertos ardientes de donde nos llegan los Charrúas, ¡que se quede ahí tan solamente cuarenta y ocho horas, y ya me dirá algo! Quiero decir que parecerá que la naturaleza misma hubiera endulzado al melón; y que la sangre noble del príncipe será como agua que ponemos sobre el fuego; su sangre hervirá, su cabeza se exaltará hasta la audacia, hasta la temeridad, y en vez del pacífico conquistador de Amberes, en vez del héroe científico, en vez del gran capitán con conceptos ingeniosos pero fríos, tendrán a uno de los mayores asesinos que hayan nunca florecido y mascado tabaco, bajo el cielo ardiente del Uraguay (sic).

Pero volvamos a nuestros salvajes.

$4^{\circ}$ La joven Michaela, o mejor dicho Guynausa (sic), de la que todos nuestros colegas del gran formato acordaron celebrar la dulzura, la gracia, los ojos cortados oblicuamente, y el gusto pronunciado por el bello Tacuabé tanto como para el tabaco de mascar. Es apenas si la mismísima señorita Ad.... le gana en belleza a la joven ex110 tranjera. La señorita Ad.... Tan solamente tiene sobre ella una ventaja incontestable, la de no ser salvaje.

Así es en pocas palabras la interesante familia real a la que las últimas revoluciones de Sudamérica han derrocado el trono, o sea la choza, y que han echado hasta nuestro continente, tal cual volcán tirando a lo lejos su polvo. Si siente la curiosidad de conocerla mejor, e incluso de tener el honor de fumar en toda familiaridad un cigarro con su majestad derrotada, ya conoce su dirección. Vaya, vaya, créame. La visita solo cuesta 2 francos; es menos que el Journal des Connaissances utiles (4 fr. por año); y es cierto que el Journal des Connaissances utiles nunca logrará darle algo tan útil como esto. Hay mucho por meditar sobre la vanidad de las cosas de este mundo, incluso Le Constitutionnel, al ver estos nobles vestigios de una dinastía otrora tan floreciente. "iQué lástima! Pensaba tristemente, contemplando respetuosamente esas augustas curiosidades, así es el final inevitable de todas las potencias de la tierra, sobre todo en este siglo perverso, en el que tan solo encontramos en los grandes caminos a monarcas caídos, como en las calles de París se encuentran piedras de los monumentos! ¡Quién puede responder que todas las dinastías de las que gozamos hoy en Europa no se verán un día expulsadas como esa! (...)

¡Quién puede contestar, lamentablemente! Que nuestra propia dinastía, que tiene más que nada un pensamiento inmutable, que también tiene ministros, que puede enorgullecerse del sufragio unánime, y a la que solo le faltan sus doce bastillas, - ¿qué puede contestar a que no será reducida a errar también algún día por los desiertos del Uraguay (sic), como Perú y los suyos por entre las poblaciones de Europa? ¿Quién puede negar que tal jefe de esta gloriosa dinastía no se hará mostrar por un conductor a los pasantes Charrúas, por la bagatela de algunas rodajas de carne de vaca, lo que es al parecer la moneda del país? ¿Quién puede responder finalmente que tal princesa de 
Francia, de la que habrá sido las delicias y el ornamento, no irá a su vez hacer hablar las malas lenguas del país sobre la naturaleza y la cantidad importante de sus relaciones; hacer contar sus amantes, no a partir de las cicatrices de sus brazos, pero de las arrugas de su cara; y finalmente, importando al desierto sus costumbres de París, preparar cerezas en aguardiente para los bebedores del Uraguay (sic), como la bella Michaela prepara hoy cigarros para los fumadores de Francia?

"Nos encontramos sin duda lejos de un tal evento; la dinastía actual está demasiado sólidamente sentada en el presente para tener nada que temer que se le asemeje, de aquí a unos cuantos siglos; sin duda tendremos todavía que rogarle al cielo que la proteja siempre, tan eficientemente como protege a Francia sobre nuestros escudos de cien sous 9 . (...)

He aquí por qué habría que invitar a todos los príncipes de la tierra a disfrutar de la ocasión y a venir a meditar sobre los Charrúas, sus colegas derrotados.

Es lo que los nuestros harán sin duda, tan pronto como el precio de entrada haya disminuido de mitad."

El artículo no lleva firma, pero sabemos que el jefe de redacción fue para esos números el después famoso Louis Desnoyers, que se destacaría también con el seudónimo Derville y que sería el principal fundador de la Société des Gens de Lettres, junto a Victor Hugo, Lamennais y Alejandro Dumas. Gran defensor de la libertad de prensa. Ya el título indica que es una crítica del rey y de la corte y las comparaciones entre la familia real y los Charrúas alimentan el objetivo satírico del artículo, que también ataca al diario Le Constitutionnel al que se enfrenta políticamente. Las comparaciones desembocan en una analogía entre el destino de esa corte de Charrúas y la que podría conocer la de Francia. El artículo termina con una alusión directa a la avaricia del rey, algo que debemos asociar a su política económica.

9. Escudos de cien "sous" designa a una moneda, en la que en ese momento aparecía el rostro del rey. 


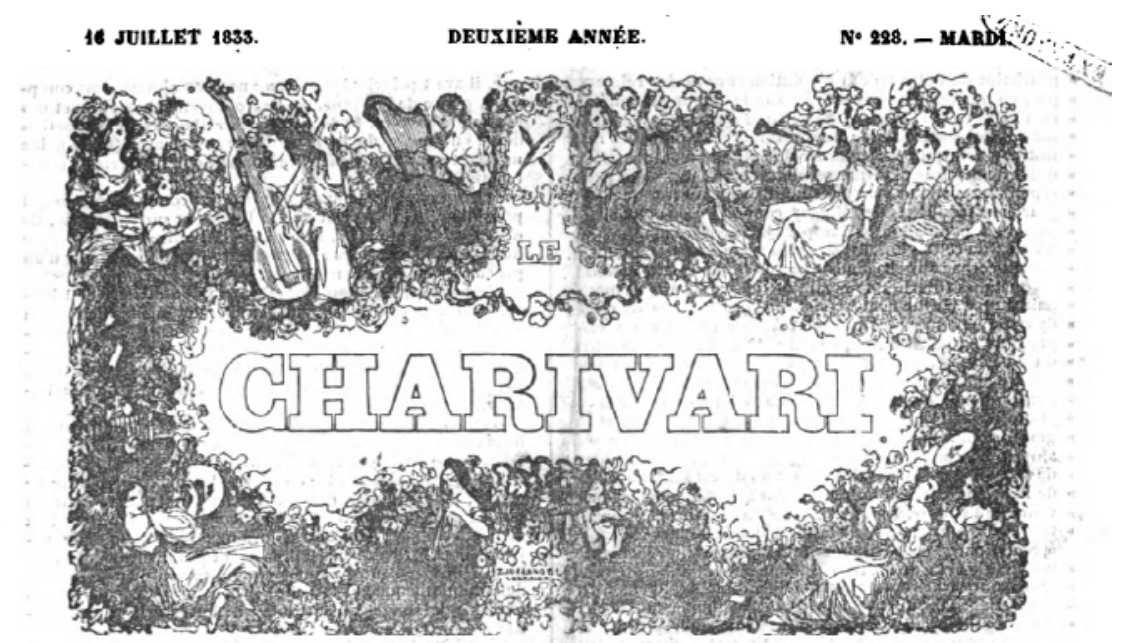

JoURNal PUbliant CHaQUe joUn UN NOUVEAd DESSIN.

\begin{tabular}{|c|c|}
\hline 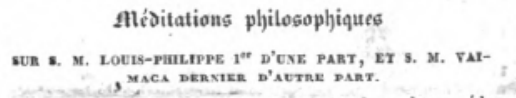 & $\begin{array}{l}\text { quer. Cest à peine si mademoiselle Ad...... elle-même l'em- } \\
\text { porte en beauté sur la jeune étrangère. Mademoiselle Ad...... } \\
\text { n'a réellement sur elle, qu'un avantage incontestable, celui } \\
\text { de n'étre pas sauvage. }\end{array}$ \\
\hline 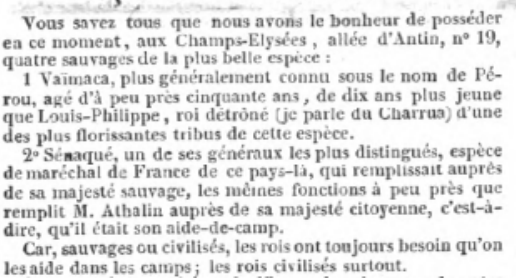 & 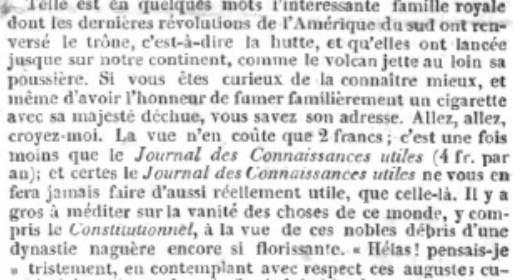 \\
\hline
\end{tabular}

En la edición del 17 de julio, el mismo Charivari, una vez más en primera página, publica otro artículo, esta vez intitulado "Soberrrrrrbiaentrrrrrrevista - De su majestad el Rrrrrey VAIMACA ULTIMO [derrrrrnier] de los Charrrrrrruas;” El autor, que es seguramente el mismo que el del artículo del día anterior, prosigue con su idea y esta vez imagina cómo sería la visita de la corte francesa a los Charrúas :

"Para Hacerrrrr pendant a la famosa entrrrrrevista de Tilsitt".

(La entrevista tiene lugar en una casa de los Campos-Elíseos, allée d'Antin, $n^{\circ} 19$, precio : 1 fr. por persona).

Cada época tiene sus solemnidades particulares, las que no difieren de las demás sino por la forma y que se les parecen en el fondo. El imperio tuvo sus batallas en el extranjero, la monarquía ciudadana tiene sus batallas en el interior. St-Méry puede muy bien figurar al lado de Marengo. Hay solo disimilitud en el nombre, la fecha, el lugar, la importancia, el objetivo y la naturaleza de los combatientes. Es poca cosa.

Sin embargo, la realeza ciudadana, al no tener beso fraterno para imponer a otra realeza europea, sobre algún río del Norte, sin duda por falta de victorias, la realeza ciudadana debería sustituirlo, si me hiciera caso, por una ceremonia del mismo tipo, es decir dándole un amistoso apretón de manos al rey derrotado de los Charrúas. El precio

10. Los Tratados de Tilsit fueron dos acuerdos firmados por el Emperador Napoleón Iero de Francia en la localidad de Tilsit en julio de 1807. 
al que ese desgraciado monarca puso la visión de su persona y la de su augusta familia, Senaqué, Tacuabé y Michaela, ese precio habiendo sido reducido a la mitad ayer, para poner su majestad al alcance de todos los bolsillos y de todas las inteligencias, la corte ciudadana podría aprovechar la ocasión.

He aquí sin duda cómo se desarrollaría la cosa. - Vamos con gran pompa al palacio de los Charrúas. El príncipe Rosolin habiendo ya pasado la edad de la infancia, estaría obligado a pagar su entrada como las personas adultas. Por otra parte, S. M. Vaimaca solo podría verse extremadamente sensible al trámite de su augusto colega.

Senaqué, el edecán del primero, también conversa muy amigablemente con el $\mathrm{Sr}$. Athalin, el edecán del segundo. Le pregunta cómo ayuda a S. M. Louis-Philippe en los campos; a lo que el Sr. Athalin contesta que Louis-Philippe ni siquiera tiene campo para nada; lo que hace que Senaqué se extraña que al no tener ningún campo LouisPhilippe, tenga un edecán. ¡Cada idea se les ocurre a los salvajes!

El joven y sano Tacuabé, príncipe real del Uraguay, parece, por su lado, disfrutar mucho al ver de cerca al joven y sano Rosolin, príncipe real de Francia; y finalmente nada puede dar una idea de la extrema satisfacción que las dos princesas Guynasa y Adelaida sienten de manera recíproca al conversar. Estas dos encantadoras personas se besan con la mayor cordialidad; hablan de ropa durante más de dos horas. ¡Ah mujeres i i Mujeres ! ¡Princesas o no, salvajes o no, Francesas o Charrúas, son en todas partes las mismas, amables, pero frívolas!

Sin embargo, Michaela, que es salvaje, le preguntó a la Srta Adelaida, que no lo es, si tenía alguna relación.

- ¡Ah! ¡Qué horror! Contesta la virtuosa francesa.

- No hay horror en tener una, retoma la Salvaje. Es algo totalmente natural para nosotros y puede ver que me acomodé perfectamente a la costumbre. Regla general: las personas de nuestra estirpe deben ser las primeras en dar el ejemplo en todo.

- ¡Pero qué! ¿Esas cicatrices en su brazo?

- Claro, es la historia de mis amores. Cada cuchillazo representa una nueva pasión. Es así que escribo a la izquierda las inconstancias de mis amantes y a la derecha las mías. Como lo puede ver ya tengo los dos brazos bastante decorados, sobre todo el derecho.

- ¡Santa Virgen, qué país singular el suyo!.... un país en el que las mujeres exhiben todos los secretos de su corazón!

- Está de moda. Dicen que ustedes europeas, disimulan más. Cada cual con su gusto; yo encuentro que la franqueza vale más. Pero a propósito, querida amiga, ¿le ofreceré un poco de este tabaco para masticar? Está excelente.

- ¡Ahi i paso!

- ¿O quizás este pequeño cigarrillo?

- ¡Ah $i$ iQué horror! ... Soy yo que quiero ofrecerle este pequeño frasco de colonia... ¡En buena hora, al menos! ¡Hábleme de esto!... Es algo que huele bien.

- ¡Puaj! ¡Puaj! ¡Cómo pueden ponerse tales hedores bajo la nariz en este país!

Enfín, la conversación continúa mucho tiempo en ese tono.

Mientras tanto, los dos jóvenes héroes conversan también por su lado. Tacuabé le muestra al hijo del rey sus armas, su arco, sus flechas, su lazo y sus boleadoras; después examina la espada de éste, y la encuentra particularmente liviana. - ¡Hey! ¡Cómo! Le dice, ¿es con esto que vas a la guerra ?... Pero me parece que no se mataría ni a una mosca con tales armas!

- Y bueno, contesta el joven europeo, están hechas para no matar a nada.

- ¿Y para que la llevas puesta? 
- Para protegerme tu vida?

- ¡He ahí algo bien especial! Pero a propósito, ¿cuántos enemigos has matado en

- Ninguno

- ¿Ninguno? Pretendes, sin embargo haber ya varias veces estado en guerras. ¡Dios! Ustedes europeos, me parecen ser bastante originales!

Por su lado, S. M. Francesa se empalmaría con su majestad Charrúasina y le haría mil preguntas sobre los usos de su reino. - "Tenía usted también un pensamiento inmutable?" le preguntaría.

-De ninguna manera, contesta el monarca salvaje. Ni siquiera tenía algún pensamiento.

- Pero entonces, ¿cómo gobernaba a su pueblo?

- En realidad, no lo sé bien... Se gobernaba por dios, bien solo, y las cosas no iban tan mal.

- ¿Tenía por lo menos una lista civil?

- No más que pensamiento. Tenía rebaños de vacas mías. Era mi fortuna particular, y como era inmensa, en vez de hacerme pagar por mi pueblo era yo quien les pagaba.

- ¡Ah! ...iperdón!.. Pero una cosa todavía... ¿Cumplía usted de manera escrupulosa las promesas que le había hecho a su pueblo?

- No hubiera dejado de cumplirlas. Mis fieles sujetos me habrían hecho asar en mi choza.

- Cuando tenía aliados, y que se les atacaba, ¿cómo se portaba su diplomacia?

- Mi diplomacia no se portaba. Volábamos todos a socorrerlos. Aquel que tiene amigos y los abandona es un egoísta, un traidor y un cobarde. Por otra parte, proseguiría el Salvaje, le agradezco por la visita que me hizo. Si algún día le toca ir a pasearse por lo de mis antiguos sujetos, ruego al cielo que le procure por allá tan agradables visitas como ésta. Deseo devolverle un día la amabilidad yo mismo.

La entrevista se terminaría ahí.

- Es particular, diría S.M. Francesa, volviendo a su casa; ¡es particular, las ideas barrocas de esa gente! Se nota que son Salvajes. ¡Qué gente rara! ¡Pero dónde puede estar situado ese diablo de Paraguay!

- El Paraguay, podría contestar ingenuamente alguno de los hijos de S.M. ¡Oh! Yo sé lo que es... he visto ese nombre en algún lugar... ¡Paraguay, Paraguay!... he visto eso en Le Constitutionnel... en la columna de los avisos...! Si! Eso es... el ParaguayRoux, Solo que no sé por qué se le dice roux ${ }^{11}$, porque tienen el pelo totalmente negro!

- Desde luego, retrucaría entonces la princesa, negros o pelirrojos, me da igual; pero lo que sí es seguro, es que es un país bien deprimente ese en el que las mujeres se ven forzadas, por la costumbre, a tajarse los brazos, cada vez que cambian de amoríos, como hacen los panaderos para marcar los panes que se consume. ¡Es un país aún bien indecente!"

En este nuevo texto satírico, el autor vuelve a criticar la avaricia del rey pero esta vez denuncia también su lejanía de los campos de batalla, algo que le habrá costado, siempre según el autor, no poder saludar otras cortes europeas prestigiosas. El diálogo entre Micaela Guyunusa y la princesa Adelaide ${ }^{12}$, hermana menor de Louis-Philippe, permite un cuestionamiento de los valores morales de la familia real.

11. Roux designa en francés el color rojizo y en particular el pelo de quienes son pelirrojos.

12. Adelaïde d'Orléans (1777-1847). 
El 22 de julio el Charivari habla una vez más de los Charrúas, esta vez para abarcar la crisis con los reinos de España y de Portugal:

"¿ Veremos nuevamente Don Pedro en el Hotel de Bragança o don Miguel vendrá al contrario a crear, en alguna bicoque de los campos-Elíseos, o en alguna jaula del Jardín des Plantes, una peligrosa competencia a su colega derrotado, el Cacique de los Charrúas?"

El Charivari publicaría otro texto que Paul Rivet no reprodujo en Les derniers Charrúas, el 16 de agosto, y esta vez, en segunda página, describiría la muerte de Senaqué en un pequeño artículo intitulado : ; Pobre Salvaje!

"Un hombre acaba de morir desapercibido; sin La Revue de Paris ${ }^{13}$, quizás lo creyéramos todavía vivo. Y sin embargo este hombre es uno de los que, durante ocho días, ocupara a París entera, junto con la hernia real, la nave de papel maché, las catorce bastillas, y la nueva edición de las obras completas de M. Crô̂te, o más bien Groult de Tourlaville.

Este hombre es uno de esos cuatro Charrúas, un miembro de esa familia real de salvajes que nos tiró América, esperando que Europa le devolviera lo mismo. Es, en una palabra, el favorito del cacique Peru, el sabio de la tribu, el médico Senaqué.

Enfermo desde antes de su llegada a París, fue transportado, el 23 de julio, a la Maison royale de santé. Fueron los Señores administradores del Jardin des Plantes que allí lo instalaron, prometiéndole cubrirlos gastos de su enfermedad. Se había previamente decidido que el monto necesario sería tomado sobre los fondos destinados a la compra de animales raros. ¡Pobre hombre! ¡Que me vengan a hablar, después de eso, de la vieja hospitalidad francesa!

El pobre no pudo nunca acostumbrarse a la blandura de una cama de hospital. Rechazó, como si fuera veneno, todas las drogas que le fueron dadas por receta del médico. Se había dicho que ese salvaje estaba dotado de un maravilloso instinto.

Murió tras haberse alimentado, durante tres días, de agua fresca, de hielo y de carne cruda. "Oh París! París!" Son las últimas palabras que pronunció.

He aquí la copia textual de su acta de defunción: "Nombres y apellidos, Senaqué, - país, Indio - edad, suponemos unos cincuenta y seis o cincuenta y siete años, - profesión, salvaje, favorito del jefe de la tribu, médico, - soltero.

El Muséum d'Histoire Naturelle reclamó su cuerpo. Le pertenecía por derecho: era el precio por la caridad del consejo de administración que había cubierto los gastos de su estadía en la Maison Royale de Santé. ¡Vaya consejo filantrópico!

El cacique Vaimaca pareció muy afectado por la muerte de su favorito. Juró que ayunaría, en señal de duelo; pero esta bella resolución no pudo aguantarse ante una canasta de ciruelas que le encantan. El reconocimiento de los reyes es igual en todas partes. Por más que les prometan amistad, devoción, fidelidad, todo vale ciruelas ${ }^{14}$.

En cuanto a Tacuabé y Guynasa (sic), la muerte de su compañero no les impidió ir a disfrutar los festejos de julio. Han incluso declarado que no habían visto nada más divertido en París que los fuegos artificiales, el palo de la cucaña, y Polichinela. Y eso que se había dicho que habían recibido la visita de la Academia de Ciencias y de la familia real.

13. Artículo redactado el 3 de agosto por Camus, internado en la Maison Royale de Santé. Les derniers moments de Senaqué le Charrúa. Revue de Paris. Paris, 1ère série, t.LII, 1833.

14. Esta anécdota, de ser verídica, coincidiría con la expresión "por ciruelas" que se emplea en francés para designar una acción inútil o cuyo resultado no tiene valor. 
En lo que al Sr. Cassette ${ }^{15}$ concierne, esta muerte le causó un gran sentimiento de placer: "ya que, dijo, si se pagaban 40 sous para ver a cuatro salvajes, solo se pagarán 30 ahora que son tan solo tres. Son 10 sous que ganamos. "Las sensaciones del $\mathrm{Sr}$. Cassette no arrancan ni desde el alma, ni desde el corazón, ni desde la sangre, ni del cerebro: no nacen en el sistema nervioso, pero si en el sistema aritmético decimal."

El Charivari denuncia de manera directa el trato que se tuvo con los Charrúas, algo que confirma la dualidad de opiniones que se tuvo en ese momento, unas décadas antes de que se multiplicaran los zoológicos humanos. Es también el estatuto científico de la medicina que es burlado, así como lo son los académicos y la familia real al ser comparados en términos de diversión con Polichinela y el palo de cucaña. El autor termina una vez más riéndose de la tacañería del rey Louis Philippe, apodado "Sr.Cassette".

En su edición del 3 de octubre, el Charivari nos informa sobre la exposición de los Charrúas, aportándonos un nuevo dato sobre ellos, en la columna "Carillon" a saber la exhibición de la niñita al parecer en compañía de su madre:

"Los salvajes Charrúas fueron transportados desde hace algunos días, a la calle de la Chaussée d'Antin, $\mathrm{n}^{\circ} 27$. Recordamos que Senaqué, el doctor de la tribu, murió hace varias semanas en la Maison Royale de Santé. Peru el Cacique le sobrevivió apenas unos días. Solo queda de esa colonia de desterrados los dos miembros más interesantes, el joven Tacuabé y su mujer Micaela. Hay sin embargo que agregarles una niñita a la que afortunadamente dio luz Micaela el 20 de septiembre. Esos salvajes atraen todos los días una cantidad importante de curiosos."

Pasaría más de un siglo antes de que se difundiera en Uruguay el relato de la triste odisea del grupo que François de Curel llevara a Francia. La imagen del indio Charrúa sería elaborada en gran parte en la segunda mitad del siglo XIX a través de obras como el Charrúa de Pablo Bermudez (1853), Abayubá de Florencio Escardó (1873), y sobre todo por el Tabaré de Zorrilla de San Martín (1888). Esta construcción transformaría al "primer enemigo de la nación uruguaya", hecho que esgrimirían como pretexto los operativos militares dirigidos por Fructuoso Rivera en 1831, en un ícono nacional. El proyecto del "indio propio" en el "país sin indios" se caracterizó por la creación de un sistema de representaciones en torno a un "indio muerto", figura mítica que aleja a esa alteridad de manera definitiva al cerrar sobre ella la tapa del olvido. El Charrúa, como indio nacional (Arce Asenjo, 2015) aparecería no solamente en la literatura sino también en las artes gráficas y hasta en el fútbol con la famosa Garra Charrúa.

A la hora de utilizar fuentes, debemos siempre considerar la particularidad de las mismas, y en este caso las de los diarios y periodistas citados en este trabajo. La descripción de los Charrúas está claramente subordinada en todas estas fuentes a otros objetivos críticos, cuya modernidad podemos, al paso, destacar. En Le Figaro se apunta claramente a la Academia y a las autoridades científicas, en le Journal des Débats Politiques et Littéraires, es la calidad del teatro que se ve cuestionada, Le voleur nos aporta una reflexión sobre la posibilidad de mostrar lo extraño como verdadero, fuera de su contexto, y finalmente, es en un plano totalmente político que se inscriben los artículos de Le Charivari.

En Uruguay, a fines del siglo XX surgieron varios autores que reivindicaron esta vez al Charrúa desde discursos rousseaunianos, asociándolo también a la Gesta Artiguista y a sus valores. Estos relatos, del Bernabé Bernabé de Tomás de Mattos, a la obra Sal-

15. Por la expresión "MrCassette", el autor designa al rey Louis-Philippe, tildándolo al pasar de avaro, ya se le llamaba "cassette" a un pequeño cofre en el que se guardaban las monedas, término que sería inmortalizado por Molière en su obra "El avaro" (1668). 
sipuedes de Alberto Restuccia, o los que desde la pluma de Gonzalo Abella y Danilo Antón acompañarían a las reivindicaciones de una reemergencia Charrúa en el país, no dejan de enfrentarnos a la misma problemática que los artículos reproducidos aquí: ¿Podremos describir una alteridad sin someterla a lo que nuestra condición determina?

Por lo pronto parece esencial al menos estudiar en profundidad el contexto de producción de las fuentes, y acompañarlo de una mirada crítica sobre nuestro propio discurso, que no está menos condicionado que aquel.

\section{Bibliografía}

Acosta y Lara, E. 1961. La guerra de los charrúas en la Banda Oriental. Librería Linardi y Risso, Montevideo.

Arce Asenjo, D. 2007. Nuevos datos sobre el destino de Tacuavé y la hija de Guyunusa. En: Romero, S. (comp. Edit.) Anuario de Antropología Social y Cultural en Uruguay 2007, pp 51-71. Editorial Nordan-Comunidad. FHCE, UDELAR.

Arce Asenjo, D. 2015. Etnónimos indígenas en la historiografía uruguaya. Desensamblando piezas de diferentes puzzles. En: Romero, S. (editora) Anuario de Antropología Social y Cultural en Uruguay 2015, pp 23-34. Editorial Nordan-Comunidad. FHCE, UDELAR.

Bouysse-Cassagne,T., Lavaud,J.P., Gomez, T. 1984. L'indien pretext, 27-44. En: Raison Présente, Nouvelles Editions Rationalistes.

Bracco, D. 2004. Los errores charrúa y guenoa-minuán. Jahrbuch für Geschichte Lateinamerikas 41. BöhlauVerlagKöln/Weimar/Wien, 2004.

Duviols, J.-P. 2006. Le Miroir du Nouveau Monde. Images primitives de l'Amérique. Presses Universitaires de Paris IV-Sorbonne.

Favre, H. 1996. L’indigénisme.- Paris, Presses Universitaires de France. - 126 p.p. Coll. Que sais-je ?

Figueira, J. J. 1977. Eduardo Acevedo Díaz y los Aborígenes del Uruguay. Boletín Histórico del Ejército. Nros 193-196. Montevideo.

Hartog, F. 1980. Le Miroir d'Hérodote: essai sur la représentation de l'autre. Gallimard, 386 pp.

Houot, A. 2007. Guaraníes y Charrúas en la literatura uruguaya del siglo XIX. Realidad y ficción. Montevideo, Linardi y Risso.

Petit Muñoz, E. 1968. Los primitivos habitantes del Uruguay. Enciclopedia Uruguaya. Arca, Montevideo.

Vidart, D. 1996. El mundo de los charrúas. Banda Oriental, Montevideo.

Pi Hugarte, R. 1992. Los indios del Uruguay, MAPFRE, España.

Pi Hugarte, R. 1999. Historias de aquella "gente gandul". Españoles y criollos vs. indios en la Banda Oriental, EUDECI/Fin de Siglo.

Rivet, Paul, 1930. Les derniers Charrúas, Société des Amis de l'Archéologie, Montevideo.

\section{Fuentes}

Le Musée des Familles del 31 de octubre de 1833

Le Figaro del 22 de junio de 1833

Journal des Débats Politiques et Littéraires del 10 de junio de 1833

Le Voleur del 15 de julio de 1833

Le Charivari del 6, 8, 16, 17 y 22 de julio, del 16 de agosto y del 3 de octubre de 1833 
